\title{
LA FATAL IGNORANCIA O DEL DERECHO DEL TRABAJO VISCERAL ${ }^{*}$
}

\author{
Claudio Palavecino Cáceres ${ }^{* *}$ \\ Universidad de Chile
}

Ya sé que casi todos los ponentes o panelistas en este Congreso han dado sus felicitaciones a sus organizadores. Aun a riesgo de ser reiterativo y, encima, consumir algunos segundos de mi escaso tiempo yo quiero insistir de todos modos en esas felicitaciones. En un momento en que muchos estudiantes, amantes de la paradoja, dicen que van a mejorar la educación precisamente paralizando las actividades académicas, contrasta luminosamente el ejemplo de todos ustedes, los buenos estudiantes que hacen lo único que sí puede mejorar la educación, estudiar. La apropiación, la aprehensión de la cultura, que no otra cosa es la educación, es un acto solitario y heroico. También quiero destacar la interdisciplinariedad de este panel, la feliz idea de abordar las vinculaciones entre el derecho con otras disciplinas y abandonar, aunque sea por un momento, el estudio del derecho del trabajo como compartimento estanco.

No niego que la parcelación de la realidad que efectúan las ciencias sea útil y acaso indispensable metodológicamente, pues nuestra percepción del mundo es, por desgracia, limitada, nunca tenemos la visión completa, el ojo de Dios, el panóptico, de manera que para abordar su conocimiento hay que delimitar objetos de conocimiento, acotarlos, pero sin olvidarse que ese parcelamiento es un ejercicio convencional y probablemente arbitrario. Cada disciplina desgarra el mundo para poder abarcar y asir, al menos, un pedacito del mismo. Pero, insisto, nunca debería perderse la consciencia de esta operación intelectual.

Uno de los grandes errores que siempre reprocho a mis colegas juslaboralistas es que conciben el Derecho del trabajo como un sistema cerrado y autosuficiente, como una realidad autónoma, inconexa y, entonces, las fórmulas, las explicaciones y construcciones teóricas que plantean están totalmente desconectadas con los otros sistemas concurrentes tales como la empresa, la economía del país, la economía mundial, las demás ramas de Derecho, etc.

No les interesa nada más que el derecho del trabajo. ¡Que viva el derecho del trabajo y que el mundo perezca! $\mathrm{Y}$ esto es un error. Un error gravísimo porque los delirios de los laboralistas muchas veces cuajan en leyes y estas producen impacto sobre la sociedad.

El derecho del trabajo está entrañablemente ligado a la Economía porque se ocupa precisamente de una porción del fenómeno económico, se ocupa de las relaciones entre capital y trabajo, de las relaciones que, con ocasión de la producción de bienes y servicios, se traban entre el poseedor del capital y el poseedor de la fuerza de trabajo. El derecho del trabajo se ocupa de las relaciones que se traban entre el empresario y el trabajador. Son relaciones de cooperación, puesto que actuando coordinadamente producen bienes y ser-

\footnotetext{
Conferencia dictada por el autor en el Segundo Congreso Nacional Estudiantil de Derecho del Trabajo, 27 de abril de 2012.

** Abogado. Profesor de Derecho del Trabajo y la Seguridad Social, Facultad de Derecho, Universidad de Chile.
} 
vicios, pero también estas relaciones dan lugar a conflictos. Hay un conflicto basal en estas relaciones porque la fuerza laboral es, al fin y al cabo, un costo más para la empresa y todo empresario que quiera sobrevivir y medrar como tal debe mantener un férreo control sobre sus costos.

A su vez todo trabajador aspira naturalmente a incrementar sus ingresos. Vivimos en una sociedad de consumo y, no nos engañemos, nuestra capacidad como consumidores determina en buena parte nuestra posición en la pirámide social, nuestra consideración social e incluso nuestra propia autoestima. Y para la mayoría de los mortales la capacidad de consumo viene determinada por el monto de sus salarios, de sus remuneraciones como trabajadores dependientes.

Es por eso que la pérdida del trabajo en muchos casos es una catástrofe en la biografía de cualquier persona. Se comprende entonces que el término del contrato de trabajo sea un tema especialmente sensible para el derecho del trabajo tradicional y que este promueva como uno de sus principios fundamentales la estabilidad en el empleo. El derecho del trabajo tradicional apuesta por mantener al trabajador en su empleo y consecuente con este objetivo rigidiza la posibilidad de salida del contrato de trabajo. Una vez que el trabajador entró a la empresa, el derecho del trabajo cierra la puerta o, todo lo más, deja apenas un portillo. Con tal fin se inventa un régimen causado de terminación; nulidades de despidos; indemnizaciones de la más diversa índole y recargos, multas y toda una maquinaria infernal de control administrativo y judicial del despido. Lo que se querría es que el trabajador que consiguió un empleo no lo soltara más.

Pero miremos ahora el fenómeno desde la perspectiva de la empresa. Y aquí voy a repetir algo que le escuché hace un par de años, en Concepción, al profesor Dr. Eduardo Caamaño, del cual, como sabrán, me separa un océano ideológico, lo cual, sin embargo, no me ciega para reconocer que, esta vez, tuvo un destello de formidable lucidez. Caamaño dijo: "grábense bien esto: las empresas no dan trabajo; las empresas necesitan trabajo".

Lo cual es totalmente cierto, al menos a corto y mediano plazo (pues no sabemos si se cumplirán en el futuro los vaticinios sobre el fin del trabajo de pitonisos como Rifkin o Ulrich Beck o incluso de alguien harto más serio que los dos anteriores como Jürgen Habermas quien en $E l$ discurso filosófico de la modernidad vislumbra el fin de la sociedad basada en trabajo). Pero si admitimos que las empresas necesitan trabajo, vale decir, que no dan trabajo graciosamente como el magnate que arroja monedas al mendigo, entonces, hay que aceptar también la consecuencia que se deriva de esa afirmación. Si las empresas necesitan trabajo quiere decir, entonces, que las empresas tienen sumo interés en retener a sus trabajadores y que en circunstancias ordinarias no se deshacen de ellos por mero capricho o para satisfacer una sádica maldad.

¿Cuándo se toma la decisión de despedir a un trabajador? Básicamente yo diría que los motivos son dos, o se trata de velar por la supervivencia de la empresa frente a circunstancias adversas que obligan racionalizar los recursos, incluido el recurso humano o bien es que el trabajador es inepto, que no sirve.

Frente a esto el derecho del trabajo es ciego, sordo y loco. En efecto, la legislación laboral trata por todos los medios que el empresario mantenga al trabajador en su puesto; que se suicide. $Y$ para ello pone en marcha toda esa maquinaria infernal que ya hemos men- 
cionado. Se busca encarecer el despido, incrementar los costos de reemplazo del trabajador. $Y$ entonces el empresario que necesita de todos modos reducir personal (porque obviamente no se va suicidar) ya no decidirá en función de la productividad del trabajador, sino de su mayor o menor antigüedad y, como al final, la racionalidad económica siempre termina imponiéndose, el derecho laboral provocará precisamente el efecto que quería impedir: la rotación de trabajadores para evitar que cumplan la antigüedad que genera indemnización. El resultado está a la vista, en Chile las indemnizaciones por término de contrato las terminan percibiendo cuatro gatos. De acuerdo a los estudios, solo un $6,44 \%$ de las personas que son despedidos, cumplen las condiciones que les permiten acceder a indemnización. Es decir, cerca de $94 \%$ de las personas que trabajan, al ser despedidos, no tiene derecho a ellas. Y menos de $20 \%$ de los trabajadores que tienen derecho a indemnización por años de servicio logran cobrar al menos una parte de su crédito. Este $20 \%$ que cobra es equivalente a un $1,25 \%$ del total de las personas que pierden el empleo, que tenían contrato indefinido y que trabajan un año o más en la misma empresa.

Ahora, ustedes me dirán, puede ser cierto lo que dice profesor, pero usted mismo acaba de afirmar que perder el trabajo es una catástrofe en la biografía de cualquier persona, y así es, efectivamente, en cuanto el cesante queda temporalmente privado de sustento, y probablemente también su grupo familiar quede en la misma precaria situación. Evidentemente que desde esa visión solidaria de la sociedad que tanto les entusiasma a los jóvenes y en general a la gente romántica, la sociedad tiene un problema, a saber, cómo reemplazar el salario del trabajador durante el lapso que tarda en volver a emplearse, de manera que ni él ni su familia caigan en la indigencia. Y en ese contexto, si ustedes me colocan en la disyuntiva entre seguro de cesantía versus indemnizaciones, evidentemente me quedo con el primero. Y si me apuran, yo defendería seguro de cesantía y libre despido, desactivar de una vez por toda esa maquinaria inquisitorial frente al despido. Ese sería mi mundo ideal. Pero no me ilusiono, de una parte porque no existe auténtica voluntad ni respaldo político para una reforma en tal sentido $y$, por otra, porque el laboralismo tradicional que tanto les gusta a ustedes se resiste visceralmente a cambiar su lógica antiliberal e intervencionista, la lógica de la estabilidad en el empleo por la de la empleabilidad.

Nunca van a entender que la mejor protección para los trabajadores no proviene de la ley laboral sino del pleno empleo. Si quieren mejorar los estándares de vida de nuestros trabajadores tendrán que abogar no por más, sino por menos derecho del trabajo. Muchas gracias. 